\title{
REVIEW ARTICLE \\ Human Resource Requirement Under the Context of Universal Health Coverage (UHC) in Bangladesh: Current Situation and Future Challenges
}

\author{
*MHK Talukder ${ }^{1}$, MM Rahman², M Nuruzzaman ${ }^{3}$ \\ ${ }^{1}$ Professor Dr. Md. Humayun Kabir Talukder, TNP-HRH, WHO Country office, Bangladesh \\ ${ }^{2}$ Professor Dr. Md. Mahfuzar Rahman, Head, Department of community medicine, Anwer Khan Modern Medical \\ College (AKMMC), Dhaka \\ ${ }^{3}$ Mr. Md. Nuruzzaman, HRH Technical Assistant (WHO), HRM Unit, MOHFW \\ *Corresponding Author \\ Date of submission: 01 March 2015 \\ Date of acceptance: 16 April 2015
}

\begin{abstract}
"Human resources" have been described as "the heart of the health system in any country". The fact of health worker shortage in Bangladesh is well documented and regarded as one of the major challenges of the country's health system as mentioned in the national health policy 2011 and also in the strategic plan for health, population and nutrition sector development programme (HPNSDP 2011-2016). Universal Health Coverage (UHC) has got immense attention around the world. This is true that Bangladesh has been able to achieve remarkable progresses on the overall health status. However, considering the growing needs of the health system and rapid transition in the disease pattern (e.g. from communica ble to non communicable), long way to go towards a responsive, competent and equity based health system.
\end{abstract}

Key Words: Human resources, Universal Health Coverage (UHC), Bangladesh

\section{Introduction}

"Human resources" have been described as "the heart of the health system in any country", "a fundamental component of health system strengthening", "is the critical element in the effective delivery of health services". Performance of the health system is immensely dependent upon how this human resource is developed, managed, and retained. Despite of their importance there is a consensus that human resource (HR) has been given less emphasis for strengthening health systems in low income countries. HR has got much attention around the world when the World Health Report ${ }^{1}$ 2006 "Working together for Health" published. The report revealed that there was approximately 4.3 million health workers shortage across the world and also identified total 57 countries that had severe shortage. The calculation was made based on a density threshold of physician, nurse and midwife of 22.8 per 10,000 populations. Countries which fall under this density were categorized in the list of severe shortage of human resources. Bangladesh was identified as one of those countries. The fact of health worker shortage in Bangladesh is well documented and regarded as one of the major AKMMC J 2015; 6(2): 34-39 challenges of the country's health system as mentioned in the national health policy 2011 and also in the strategic plan for health, population and nutrition sector development programme (HPNSDP 2011-2016).

In-spite of this shortage, Bangladesh's progress towards achieving MDG goals has been remarkable and applauded in the international arena. A recent lancet publication ${ }^{2}$ has described this achievement due to pluralistic nature of the health system where there are multiple stakeholders from all sectors public, private, informal, non-government organizations, associations, and faith based organizations, significantly contributed towards this achievement. It is forecasted that Bangladesh will achieve most of the targets on and before 2015 . Universal Health Coverage (UHC) has got immense attention around the world. International development organizations such as United Nations (UN) have already indicated that UHC is going to be one of the post 2015 global agenda to be offered. In December 2012, the UN general assembly ${ }^{3}$ called upon all governments "urgently and significantly 
Human Resource Requirement Under the Context of Universal Health Coverage scale up efforts to accelerate the transition towards universal access to affordable and quality health care." Like many other countries such as India, Nepal, and Maldives, Bangladesh also has joined the race and announced its commitment towards achieving UHC as reflected in the "Bangladesh Health Financing Strategy 2012-2032". HR has been regarded as a challenge in this connection.

In last one decade some notable steps were made for improvement of the areas of HR management and development at national level by the government along with the development partners (e.g. an individual HR operation plan was formulated under the HPNSDP 2011-16). Since there is a huge shortage of skilled HR in the country, it is important that the country has some specific guidelines regarding categories of $\mathrm{HR}$ production to meet the requirement when the country is looking forward to achieve UHC within a given period of almost 18 years. It is important to know what categories of health workforce is needed and what is their numbers and how they are going to contribute to the health system. HR plan and projection at national level have not been done. HR needs and health systems demands have not been drawn. This paper will briefly present a general discussion on HR requirement of the country for achieving UHC in the health sector. The paper will also shed light on identifying major challenges and opportunities for overcoming HR shortage in the country.

\section{Background HRH dimensions and UHC}

The World Health Organization4 (WHO) has defined UHC as the goal that "all people obtain the health services they need, of good quality without suffering financial hardship when paying for them". For countries to achieve and sustain UHC they need to consider how they will address the following three dimensions of health coverage:

1. Reducing direct, out of pocket payments and increasing the share of healthcare costs covered from pre-paid pooled funds;

2. Increasing the share of population coverage

3. Increasing the number of service coverage

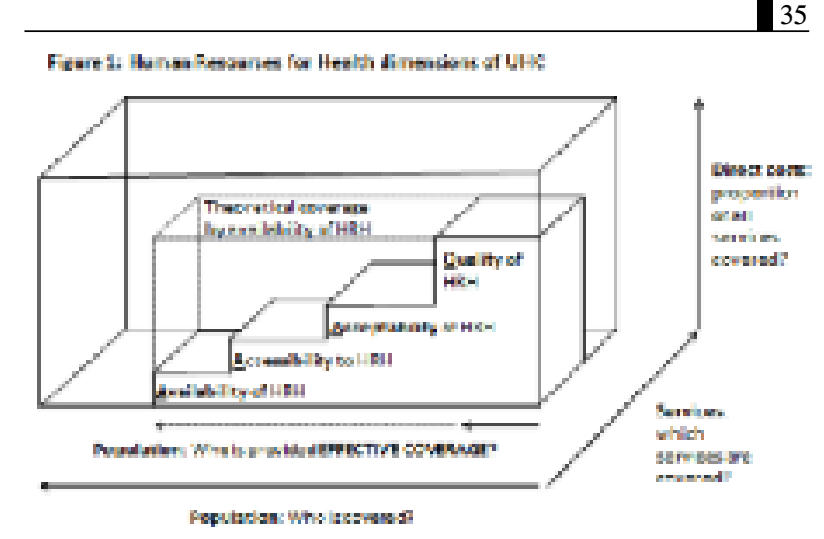

Source: Campbell et. Al. 2013

Considering the complex service nature of the HRH, WHO has identified four critical dimensions of $\mathrm{HRH}$ at the core of effective coverage which are such as availability, accessibility, acceptability and quality (in a nutshell they are called "AAAQ") ${ }^{5}$. All four dimensions are sequentially inter-connected. Without sufficient availability, accessibility to health workforce cannot be guaranteed. Even availability and accessibility are ensured without acceptability the population may not use the health services. When question against the quality of the workforce is raised, effect on provided services in terms of improving health outcomes will be sub-optimal. Hence it is important to address all four dimensions of HRH in order to achieve UHC. Countries should adopt adequate HRH policies and strategies in order to ensure effective coverage.

\section{Challenges \\ Availability}

The first prerequisite for ensuring necessary healthcare services is to availing right number of healthcare provider. Since human resource play a critical role in delivering of health services, it is imperative that the health planners and policy makers ensure right number of health workers, with right skills, is at the right place on the right time, to deliver right health services to meet the health needs of the population at an affordable cost.

\section{Approaches towards determining HR requirement at national level}

There are factors or variables which influence the determination of future health workforce requirements. Typically, these include: demographic growth and change; health policy and related 
legislation; technological change; burden of disease; service and provider utilization; relevant service quality standards; organizational efficiency; skills mix; individual provider performance; public demand and expectations; and availability and means of financing. For example, changes in the birth rate and in policies on maternal, newborn and child health services have an impact on the age profile of a given population as well as the service delivery environment and its staffing (such as shifts in the needs for midwifery personnel and their deployment, as well as for specialists to serve an ageing population). To project future health workforce requirements the approaches are:

\section{The workforce-to-population ratio method}

This is a simple projection of future numbers of required health workers on the basis of proposed thresholds for workforce density (e.g. physicians per 10000 population). This approach is least demanding in terms of data. It does a little to explicitly address other key variables (such as HIV prevalence, malaria and other communicable and non-communicable disease specific rate), aside from population growth that can be expected to affect the type and scale of future health services provision and the associated workforce.

\section{The health needs method}

This is a more in-depth approach that explores likely changes in population needs for health services, based on changes in patterns of disease, disabilities and injuries and the numbers and kinds of services required to respond to these outcomes.

\section{The service demands method}

This approach draws on observed health services utilization rates for different population groups, applies these rates to the future population profile to determine the scope and nature of expected demands for services, and converts these into required health personnel by means of established productivity standards or norms.

\section{The service targets method}

This is an alternative approach that specifies targets for the production (and presumed utilization) of various types of health services and the institutions providing them based on a set of assumptions, and determines how they must evolve in number, size and staffing in accordance with productivity norms.

Each of these approaches has its advantages and limitations. Health planners and managers must determine which variables are the dominant ones in any consideration of future requirements, including which of them are most amenable to policy intervention. In Bangladesh it is hard to find how decision on HR requirement is made. Post creation is a complex task requiring several ministries involvement and approval. According to a report published by MOHFW indicates that government has adopted staffing standards for public health facilities based on number of beds a facility holds (e.g. for a 50 bed hospital there are provisions for appointing 21 medical doctors and 15 nurses and 4 midwives). Now it is difficult to describe how this staffing norm arrived because it is hard to find any evidence or study. However, there is a lack of proper evidence how decisions on the number of posts are made in the public sectors. Concerns have been made whether considerations of HR need assessment have been conducted or not in respect of population to serve, disease burden, utilization rates, patient/client load or existence of other facilities. MOHFW had been successful to adopt the national health policy and national health plan but was little or not successful to formulate a national level health human resource plan or strategy in last more than 10 years.

\section{Need-based sufficiency of health worker}

The World Health Organization estimated a threshold of healthcare professional mix in 2006 that a country should have at least 22.8 physicians, nurse and midwives for every 10,000 population in order to deliver basic health services. These doctors and nurse/midwives need to be supported and supplemented by a wide range of other health professionals, paramedics and medical technologists.

If we apply this $1: 3: 5$ ratio to the estimated population of 180 million in 2021 , the country as a whole would require a health professional workforce of: 
Table-I: Projected requirements of medical doctors, nurses and paramedics 6

\begin{tabular}{|c|c|c|}
\hline Category & Total & requirement \\
\hline Doctor & & 103,500 \\
\hline Nurses & & 310,500 \\
\hline Paramedics & & $517,5 \quad 00$ \\
\hline
\end{tabular}

Source: Bangladesh HRH Country Profile 2013

The following figure indicates the recent collected data for the HRH Country Profile (2013), the country has the professional health workforce as registered with the licensing bodies-

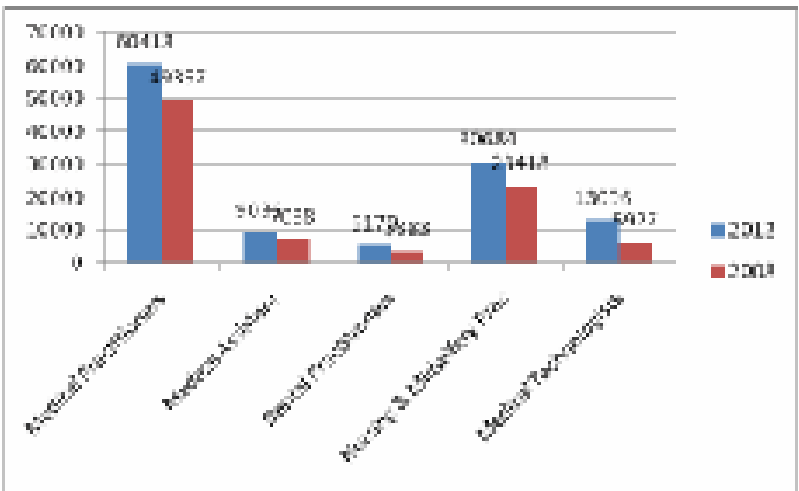

Figure-1: HR stock and trend between the year 2012 and $2008^{6}$

Source: HRH Country Profile 2013

In addition current facility based or number of bedbased staffing policy does not seem to meet the actual HR requirement of the health needs of the population.

Table-II: Current facility based or number of bedbased staffing policy

\begin{tabular}{lcccccc}
\hline Sl Hospital & \multicolumn{2}{c}{$\begin{array}{c}\text { Total in of Doctor's post } \\
\text { number }\end{array}$} & $\begin{array}{c}\text { of Nurse post } \\
\text { for each hospital }\end{array}$ & Total post \\
hospital & Doctor & Nurse \\
\hline 1 10-bed Hospital (for Upazila and Union) & 24 & 2 & 4 & 48 & 96 \\
2 20-bed Hospita (for Upazila and Union) & 24 & 6 & 6 & 144 & 144 \\
3 31-bed Hospital(for Upazila) & 151 & 9 & 7 & 1359 & 1057 \\
4 50-bed Hospital(for Upazila) & 268 & 20 & 16 & 5360 & 4288
\end{tabular}

It is clear that in the current Upazila health system in the public sector, Bangladesh has more doctor/physician posts than that of nurse which is reverse in compare to the ratio of one doctor and three nurses. In terms of production of physician and nurses Bangladesh has almost twice number of MBBS doctors than nurses (Figure-1).

\section{Accessibility}

Accessibility dimension of HRH looks upon how equity is ensured in terms of distribution of the available workforce. To ensure UHC it is essential that all people have access to a competent health worker at the right place on right time when they need. In Bangladesh geographical distribution of the health workforce has been a challenge for long time. "Bangladesh Health Workforce Strategy 2008" identified geographical imbalance of health workforce as a major area for strategic intervention. The number of health workforce is densely populated in the urban areas especially in the capital city in compare to rural areas. A recent Lancet publication (2013) indicates the following density of doctors and nurse:

Table-III: Health workforce density per 10,000 in rural and urban areas

\begin{tabular}{cccc}
\hline Serial & Level of distribution & $\begin{array}{c}\text { Doctor per 10,000 } \\
\text { population }\end{array}$ & $\begin{array}{c}\text { Nurse per 10,000 } \\
\text { population }\end{array}$ \\
\hline 1 & National & 5.4 & 2.1 \\
2 & Rural & 1.1 & 0.8 \\
3 & Urban & 18.2 & 5.8 \\
\hline
\end{tabular}

Source: Ahmed et al. 2013

Retaining health workforce in rural and hard to reach areas has been a major concern of the policy makers and health managers. Poor working conditions, inadequate pay, inappropriate performance management systems, weak supervision and monitoring mechanism, poor communication infrastructure are identified as major reasons for which health workers do not want to stay in rural settings.

\section{Acceptability}

Ensuring access to health worker will not enough, it is important to look into how the users or recipients perceive the health workers and the services they provide. If the recipients find the service poor in quality or perceive the health workers are not providing 
services in line of their expectation, they may not use their services even they are available. According to a report published by Global Health Workforce Alliance (2013), "acceptability is enhanced when users of services have access to a health workforce that meets their expectations in terms of its gender and age composition, its skills mix, its cultural and linguistic make-up and, above all, its attitudes and behaviour and perceived competencies and quality of care (respect, no discrimination, good communication and empathy)".

In Bangladesh nursing profession is female dominated around 90 percent of the nursing workforce are female. But in terms of physicians about 30 percent of the totals are female (Health Bulletin, 2013).

\section{Quality}

Now-a-days quality has got immense tension from the policy makers, academicians and also from civil societies regarding the education the future health professionals receive. A recent study on "Health Professional Education Situation Analysis7" indicates the following drawbacks of medical education in the country:

- Absence of national accreditation body for health professional education.

- Lack of qualified teaching staff and resources

- Inadequate exposure to clinical training

- Unstructured internship training program

- Inadequate provision of community-based training

- Under-resourcing of new private medical colleges

- Traditional and subjective assessment system

- Defective curriculum planning (highly centralized)

- No priority for the student who have rural background during admission

- Irrelevant and out-of-date curriculum content

- Ineffective instructional methods

- Mostly absence of inter professional education practices in the syllabus.

- Less functional national curriculum bodies (CME, BMDC)

- Weak regulatory framework

\section{Conclusion}

This is true that Bangladesh has been able to achieve remarkable progresses on the overall health status. However, considering the growing needs of the health system and rapid transition in the disease pattern (e.g. from communicable to non communicable), long way to go towards a responsive, competent and equity based health system. In this regard, human resource policies, strategies and plans also need to be formulated accordingly.

\section{Recommendations}

In order to ensure UHC, the following recommendations based on availability, accessibility, acceptability and quality can be considered in order to strengthen the dimensions of the HRH in the context of Bangladesh:

Source: Ahmed et al. 2013

Retaining health workforce in rural and hard to reach areas has been a major concern of the policy makers and health managers. Poor working conditions, inadequate pay, inappropriate performance management systems, weak supervision and monitoring mechanism, poor communication infrastructure are identified as major reasons for which health workers do not want to stay in rural settings.

\section{Acceptability}

Ensuring access to health worker will not enough, it is important to look into how the users or recipients perceive the health workers and the services they provide. If the recipients find the service poor in quality or perceive the health workers are not providing services in line of their expectation, they may not use their services even they are available. According to a report published by Global Health Workforce Alliance (2013), "acceptability is enhanced when users of services have access to a health workforce that meets their expectations in terms of its gender and age composition, its skills mix, its cultural and linguistic make-up and, above all, its attitudes and behaviour and perceived competencies and quality of care (respect, no discrimination, good communication and empathy)".

In Bangladesh nursing profession is female dominated around 90 percent of the nursing workforce are 
Human Resource Requirement Under the Context of Universal Health Coverage

female. But in terms of physicians about 30 percent of the totals are female (Health Bulletin, 2013).

\section{Quality}

Now-a-days quality has got immense tension from the policy makers, academicians and also from civil societies regarding the education the future health professionals receive. A recent study on "Health Professional Education Situation Analysis ${ }^{7 "}$ indicates the following drawbacks of medical education in the country:

- Absence of national accreditation body for health professional education.

- Lack of qualified teaching staff and resources

- Inadequate exposure to clinical training

- Unstructured internship training program

- Inadequate provision of community-based training

- Under-resourcing of new private medical colleges

- Traditional and subjective assessment system

- Defective curriculum planning (highly centralized)

- No priority for the student who have rural background during admission

- Irrelevant and out-of-date curriculum content

- Ineffective instructional methods

- Mostly absence of inter professional education practices in the syllabus.

- Less functional national curriculum bodies (CME, BMDC)

- Weak regulatory framework

\section{Conclusion}

This is true that Bangladesh has been able to achieve remarkable progresses on the overall health status. However, considering the growing needs of the health system and rapid transition in the disease pattern (e.g. from communicable to non communicable), long way to go towards a responsive, competent and equity based health system. In this regard, human resource policies, strategies and plans also need to be formulated accordingly.

\section{Recommendations}

In order to ensure UHC, the following recommendations based on availability, accessibility, acceptability and quality can be considered in order to strengthen the dimensions of the HRH in the context of Bangladesh:

\begin{tabular}{|c|c|c|c|}
\hline Availability & Accessibility & Acceptability & Quality \\
\hline $\begin{array}{l}\text { 1) A national level study } \\
\text { needs to be conducted to } \\
\text { determine health workforce } \\
\text { requirement based on } \\
\text { appropriate projection } \\
\text { model. } \\
\text { 2) Facility based or bed } \\
\text { based staffing policy needs to } \\
\text { be revisited considering that } \\
\text { the demand of HR may } \\
\text { differ region wise due to } \\
\text { different epidemiological and } \\
\text { demographic pattern. } \\
\text { 3) Determine the need of } \\
\text { nursing and para-medical } \\
\text { professionals as per the need } \\
\text { of the health systems and } \\
\text { take necessary steps to } \\
\text { establish training schools to } \\
\text { minimize the gap of the } \\
\text { numbers between physicians, } \\
\text { nurse, midwife and } \\
\text { paramedics. }\end{array}$ & $\begin{array}{l}\text { 1) Health } \\
\text { workforce needs to } \\
\text { be equality } \\
\text { distributed and } \\
\text { retained. Disparity } \\
\text { of health } \\
\text { workforce density } \\
\text { between rural and } \\
\text { urban needs to be } \\
\text { minimized. } \\
\text { 2) Supportive } \\
\text { working } \\
\text { environment, } \\
\text { safety and security } \\
\text { needs to be } \\
\text { ensured at the } \\
\text { rural health } \\
\text { facilities. }\end{array}$ & $\begin{array}{l}\text { 1) Gender -wise } \\
\text { distribution of } \\
\text { health workforce } \\
\text { needs to be } \\
\text { ensured as per the } \\
\text { needs of the } \\
\text { population as well } \\
\text { as of the health } \\
\text { system. For } \\
\text { example, } \\
\text { recruitment of } \\
\text { female gynae } \\
\text { doctors, forensic } \\
\text { medicine doctors } \\
\text { and others in all } \\
\text { district level health } \\
\text { facilities. }\end{array}$ & $\begin{array}{l}\text { 1) A national level } \\
\text { health professional } \\
\text { education } \\
\text { accreditation } \\
\text { council/board } \\
\text { needs to be } \\
\text { established for } \\
\text { ensuring } \\
\text { accreditation and } \\
\text { quality assurance } \\
\text { of health } \\
\text { professionals } \\
\text { training. } \\
\text { 2) capacity of the } \\
\text { regulatory bodies } \\
\text { such as BMDC, } \\
\text { BNC, state } \\
\text { medical faculty } \\
\text { need to be } \\
\text { revisited so that } \\
\text { their capacity } \\
\text { could be } \\
\text { strengthened. }\end{array}$ \\
\hline
\end{tabular}

\section{Conflict of Interest}

The authors have no conflict of interest to anybody.

\section{References}

1. World Health Report 2006: Working together for health, World Health Organization, Geneva.

2. Ahmed, S M; Evans, T G; Standing H; Mahmud, S. (2013); "Harnessing pluralism for better health in Bangladesh: Innovation for Universal Health Coverage Series", The Lancet. Published online November 21, 2013 (http://dx.doi.org/10.1016/ SO140-6736(13)62147-9

3. UN General Assembly 2012. Resolution on Global Health and Foreign Policy. Available from: http://www.un.org/ ga/ search/ view_doc.asp? symbol $=\mathrm{A} / 67 /$ L36accessed on 10 November 2014

4. The World Health Report 2010- Health systems financing: the path to universal coverage. Geneva, World Health Organization.

5. Global Health Workforce Alliance and World Health Organization (2014), "Universal Truth: No Health without a Workforce", Geneva.

6. GOB, Ministry of Health and Family Welfare (2013), "Human Resources for Health Country Profile, Bangladesh:" Human Resources Management Unit.

7. "Health Professional Education Situation Analysis: A 5 Country Initiative" (2013); Bangladesh, China, India, Thailand and Vietnam. 